Vol. 6, No. 3-4, 2020

\author{
Oleksii Lanets ${ }^{1}$, Oleksandr Kachur ${ }^{2}$, Vitaliy Korendiy ${ }^{3}$ \\ ${ }^{1}$ Department of Mechanics and Automation Engineering, Lviv Polytechnic National University, Ukraine, Lviv, \\ S. Bandera Street 12, E-mail: poslanets1@gmail.com, ORCID 0000-0003-1053-8237 \\ ${ }^{2}$ Department of Mechanics and Automation Engineering, Lviv Polytechnic National University, Ukraine, Lviv, \\ S. Bandera Street 12, E-mail: dingof1992@gmail.com, ORCID 0000-0003-2263-6360 \\ ${ }^{3}$ Department of Mechanics and Automation Engineering, Lviv Polytechnic National University, Ukraine, Lviv, \\ S. Bandera Street 12, E-mail: vitaliy.nulp@gmail.com, ORCID 0000-0002-6025-3013
}

\title{
DERIVATION OF ANALYTICAL DEPENDENCIES FOR DETERMINING STIFFNESS PARAMETERS OF VIBRATION ISOLATORS OF VIBRATORY MACHINE
}

Received: May 04, 2020 / Revised: August 11, 2020 / Accepted: December 30, 2020

(C) Lanets O., Kachur O., Korendiy V., 2020

\begin{abstract}
Problem statement. While designing vibration isolators, the essential attention should be paid to the safety factors such as the levels of vibration and noise, as well as to the material and the structure of isolators. In major vibratory technological equipment, there are used full-metal vibration isolators, which can be designed in the form of coil (cylindrical, conical, helicospiral) or flat (leaf-type, disc-type) springs. The problems of stress-strain analysis of metal springs used for vibration isolation of various vibratory equipment are of urgent interest among the designers and researcher. The engineering techniques of step-by-step calculation of full-metal vibration isolators of different types of vibratory technological machines are not thoroughly presented in the modern information resources. Purpose. The present paper is aimed at developing and implementing the detailed algorithm of determining the stiffness parameters of the metal coil springs used for vibration isolation of large-scale vibratory machines. Methodology. The investigations are carried out using the basic laws and principles of solid mechanics and theory of vibrations. The calculations were conducted using MathCAD software; the computer simulation of the spring's stress-strain state was performed using SolidWorks software. Findings (results) and originality (novelty). The improved design of the vibratory conveyer-separator is considered. The engineering technique of calculating the passive vibration isolators of various vibratory equipment designed in the form of metal coil springs is developed. The proposed technique is implemented while designing the vibration isolation system of the vibratory conveyer-separator. The system's operational characteristics are determined, and the computer simulation of the springs stress-strain state is carried out. Practical value. The proposed design of the vibratory conveyer-separator can be implemented in various industries (machine-building, chemical, pharmaceutical, food-processing, construction, mining, metallurgy, textile industries etc.) for conveying different loose, bulky and piecewise products, and separating them into fractions of different sizes. Scopes of further investigations. While carrying out further investigations, it is necessary to analyse the influence of the proposed design of vibratory conveyer-separator on the foundation during its operation, and to consider the necessary of applying the additional fixation systems.
\end{abstract}

Keywords: vibration isolation, operational conditions, oscillations, vibration-absorbing element, coil spring, conveyer-separator, oscillatory system, finite-element method.

\section{Introduction}

The vibration phenomenon is characteristic of all technological processes. The oscillations occur during the operation of various equipment in the form of waves of different frequencies and amplitudes 


\section{Oleksii Lanets, Oleksandr Kachur, Vitaliy Korendiy}

that can be generated by the working elements, technological tools, or driving systems. The vibration influences the equipment operation and has usually a negative effect. Therefore, the task of engineers is to minimize its influence. In such a case, a good technical solution consists in applying the compensating elements that can dampen the oscillations preventing their further propagation and helping to get rid of negative influence. For such a purpose, the vibration isolators can be used.

In order to select the optimal type of vibration isolator, it is necessary to take into account the following factors:

1. To ensure the stable direction of vibration, in most cases, it is necessary to design a reliable foundation and a rigid machine frame.

2. While performing modelling and calculations, it is essentially to take into account the weight of the machine's movable parts, as well as the weight of the material to be processes (the parts to be treated).

3. One of the first stages consists in defining the characteristics of oscillations, in particular, the amplitudes, frequencies, spectral parameters etc.

4. On the other hand, the particular attention should be paid to the operational conditions of the machine, e.g., chemically aggressive substances, low temperatures, increased humidity etc.

While designing vibration isolators, the essential attention should be paid to the safety factors such as the levels of vibration and noise, as well as to the material and the structure of isolators: all-metal, rubber-metal, or all-rubber. All-metal ones are used to dampen vibrations of equipment with a significant weight, in which comparatively large deformations may be observed with no loss in performance. In such a case, the isolator is usually equipped by the additional vibration-absorbing elements. The rubber-metal isolators are equipped by the rubber base with the metal plate (core), which controls its maximal level of deformation, or its minimal height. In such a case, it is possible to ensure the safe operation of an isolator under overloading conditions. The rubber-type vibration isolator is the most commonly used one because the rubber is comparatively cheaper and more readily available material. For vibration isolation of lightload and small-scale vibratory equipment, the synthetic or the natural rubber isolators are usually used.

\section{Problem statement}

The use of full-rubber and rubber-metal vibration isolators in large-scale and heavy-load vibration machines is not recommended due to large deformations of their surface layers causing increased wear intensity. Therefore, in major vibratory technological equipment, there are used full-metal vibration isolators, which can be designed in the form of coil (cylindrical, conical, helico-spiral) or flat (leaf-type, disc-type) springs. The problems of stress-strain analysis of metal springs used for vibration isolation of various vibratory equipment are of urgent interest among the designers and researcher. The engineering techniques of step-by-step calculation of full-metal vibration isolators of different types of vibratory technological machines are not thoroughly presented in the modern information resources. Therefore, the present paper is aimed at developing and implementing the detailed algorithm of determining the stiffness parameters of the metal coil springs used for vibration isolation of large-scale vibratory machines.

\section{Discussion of modern information sources on vibration isolation}

To a large extent, the safe and reliable operation of vibratory technological equipment depends on the characteristics of its vibration isolation system. In the paper [1], Rivin E. I. et. al. performed a thorough analysis of the principles and criterions of vibration isolation, and conducted the experimental investigations which substantiated the fact that the passive vibration isolators ensure the sufficient damping characteristics in most cases of vibratory machine operation. In [2], Carrella A., Brennan M. J., Waters T. P. stated that the frequency range, within which there is provided the optimal operation of a passive vibration isolator, depends on the rigidity of its fixation to the machine frame, which is usually predetermined taking into account static or dynamic loadings. In order to verify the correctness of the stated fact, the authors studied the vibratory system consisting of one vertical and two inclined coil springs, and defined the dependence of the springs' geometry on their stiffness which provides the system with zero dynamic 


\section{Derivation of analytical dependencies for determining stiffness parameters of vibration isolators...}

stiffness in the state of static equilibrium. The same diagram of the springs' fixation was considered by Kovacic I., Brennan M. J., Waters T. P. [3]. The static analysis of the system was carried out; the parameters ensuring quasi-zero dynamic stiffness in the equilibrium position were defined; the asymmetric disturbance of the system was considered; the nonlinearity effects were studied, and the damping influence on the bifurcation phenomenon was analyzed. The works of Zhou N., Liu K. [4] are dedicated to investigation of a new type of vibration isolator, which can operate as passive or as semiactive one. The presented property of the HSLDS-isolator was obtained due to connecting the mechanical spring in parallel to the magnetic spring consisting of electric and permanent magnets. The stiffness of the magnetic spring can be positive or negative depending on the current polarity in electromagnets. The problems of design optimization and operational efficiency of the improved vibration isolator were considered. In the paper [5], Jazar G. N., Mahinfalah M., Deshpande S. investigated the passive linear vibration isolators ensuring effective isolation under the conditions of high-frequency and low-amplitude vibrations. The implicit function was derived for the frequency characteristic of the symmetric system of bilinear vibration isolator being under the conditions of steady-state harmonic disturbance.

In [6], Narimani A., Golnaraghi M. E., Jazar G. N. analyzed the linear vibration isolators developed for providing optimal interrelations between isolation and technological functions of machine. The averaging (smoothing) method was used for investigating the frequency characteristic of symmetrical partially linear isolator under the conditions of resonance. It was established that the damping coefficient plays much more important role than the stiffness while considering partially linear vibration isolators. In [7], [8], Ni Y. Q., Ko J. M., Wong C. W., Zhan S. proposed two improved Bouc-Wen models for describing the dynamic behavior of vibration isolators made of multiwire cable. The technique of defining the model's parameters was developed on the basis of experimental results carried out under cyclic loading. The dynamic behavior modelling of the isolation system made of multiwire cable was carried out for the stress-strain conditions of shear, torsion, tension, and compression. It was established that amplitude-frequency characteristics (frequency-response curves) of the system being under the conditions of tension-compression are significantly different from the ones being under the conditions of shear and torsion. In [9], there is presented the improved vertical suspension system, which utilizes the properties of column springs operating under Euler buckling conditions, and allows the minimization of the springs mass, increasing the resonance frequency, and ensuring almost ideal vibration isolation. The paper [10] presents the approach of designing the compact springs ensuring the possibility of controlling their height causing negligible change in the fundamental operation frequencies. The approach is based on the theory of thin shells. The general model of a simple spring element with "negative" stiffness was proposed. The technique of calculating the geometrical-stiffness parameters of the springs was developed. The results of theoretical modelling were compared with the results of experimental investigations. The paper [11] is focused on the analysis of possibilities of ensuring the optimal vertical vibration isolation with the help of mechanical springs. The new method of vibration isolation consists in using the Euler columns subjected to the elastic bending. The general design of the improved highly-efficient vertical vibration isolation system is proposed, and its operational characteristics are considered.

The paper [12] authored by Dyrda V. et al. considers the viscoelastic properties of rubber. On the basis of the developed mathematical model, the time dependencies of the amplitudes of the machine's frame vibrations, and the coefficient of isolation efficiency were analyzed taking into account the material ageing of the spring elements. The paper [13] presents the analysis of influence of vibration on a tractor cab during its operation. While performing the study, the rubber vibration isolators were considered, and their damping characteristics were theoretically and experimentally tested. In [14], Yilmaz C., Kikuchi N. considered the improved passive vibration isolator which is characterized by a number of "stop-points" in the wide range of low frequencies of the machine operation. The advantages of classic passive vibration isolators are discussed in [15]. The special attention is paid to isolators consisting of a viscous damper and a spring element placed in parallel. The comparative analysis of different types of passive vibration isolators is carried out, and their operational characteristics are thoroughly studied. In [16], Valeev A., 


\section{Oleksii Lanets, Oleksandr Kachur, Vitaliy Korendiy}

Kharisov S. considered the vibration isolators with low or quasi-zero stiffness that are characterized by low natural frequency of about $1 \mathrm{~Hz}$. The materials used for their manufacturing were considered, and the calculations of isolators with the working loading in the range of $1 \ldots 1000 \mathrm{~kg}$ were carried out. In the works of Fiebig W., Wróbel J. [17], there were substantiated the efficiency of double-stage vibration isolation system of vibratory conveyer mounted on foundation. During the conveyer operation, the foundation is subjected to the action of vibrations of large amplitudes. On the basis of the performed mathematical modeling and experimental investigation, there was reached the sufficient decrease in vibrational influence of the conveyer on the foundation.

\section{The purpose and the goals of the study}

The purpose of the study is to develop the engineering technique of calculating the passive vibration isolators of various vibratory equipment designed in the form of metal coil springs. The proposed technique is to be implemented while designing the vibration isolation system of the vibratory conveyerseparator. The system's operational characteristics are to be determined, and the computer simulation of the springs stress-strain state is to be carried out.

\section{Statement of the main material}

The general design of the vibratory conveyer-separator is presented in Fig. 1. The suspension and vibration isolation system consists of four metal cylindrical coil springs $(n=4)$. In the state of rest, the springs are subjected to the action of the machine mass $m=162.33 \mathrm{~kg}$.

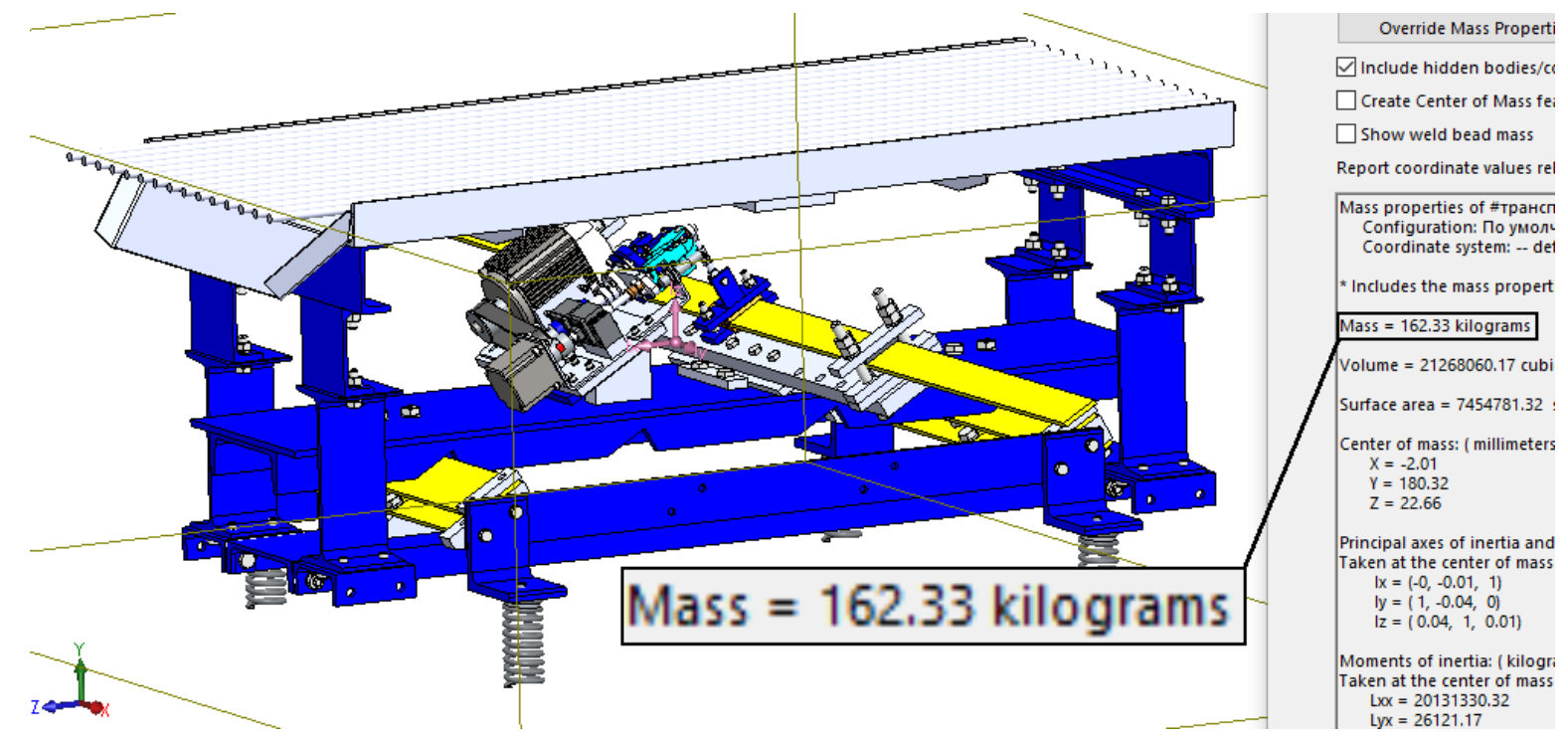

Fig. 1. The fragment of the SolidWorks software window with the presented inertial parameters of the vibratory conveyer-separator

The presented design of the conveyer-separator can be considered as the single-mass mechanical oscillatory system characterized by the stiffness $c_{i z}$. The natural frequency of the single-mass vibration isolation system must be $4 \ldots 20$ times smaller than the forced frequency of the machine operation [18]. In such a case, let us adopt the resonance correction coefficient equal to 4.28 , and the following natural frequency of the vibration isolation system's oscillations $v_{i z}=3.7 \mathrm{~Hz}$. Such a condition is sufficient for ensuring minimal values of dynamic loads the foundation is subjected to. This fact eliminates the necessity of using additional vibration isolation facilities, e.g., dynamic dampers etc. The stiffness of vibration isolators can be determined using the following formula:

$$
c_{i z}=m\left(\frac{\omega}{z_{i z}}\right)^{2}=m\left(2 \pi v_{i z}\right)^{2},
$$




\section{Derivation of analytical dependencies for determining stiffness parameters of vibration isolators...}

where $m$ is the total mass of the conveyer-separator; $\omega$ is the forced frequency; $z_{i z}$ is the resonance correction coefficient; $v_{i z}$ is the natural frequency of the vibration isolation system's oscillations.

Based on the Eq. (1), the following equation for calculating the natural frequency $v_{i z}$ of the vibration isolation system can be derived:

$$
v_{i z}=\frac{1}{2 \pi} \sqrt{\frac{c_{i z}}{m}} .
$$

Taking into account the fact that the conveyer-separator is designed for efficient operation at the nominal frequencies of $15 \ldots 16 \mathrm{~Hz}$, and considering the adopted values $v_{i z}=3.7 \mathrm{~Hz}, z_{i z}=4.28$, let us calculate the stiffness (spring ratio) of one coil spring of the machine's vibration isolation system:

$$
c_{i z 1}=\frac{m\left(2 \pi v_{i z}\right)^{2}}{n}=\frac{162.33 \cdot(2 \cdot 3.14 \cdot 3.7)^{2}}{4}=21933.2 \mathrm{~N} / \mathrm{m}
$$

where $n$ is the number of coil springs (see Fig. 2).

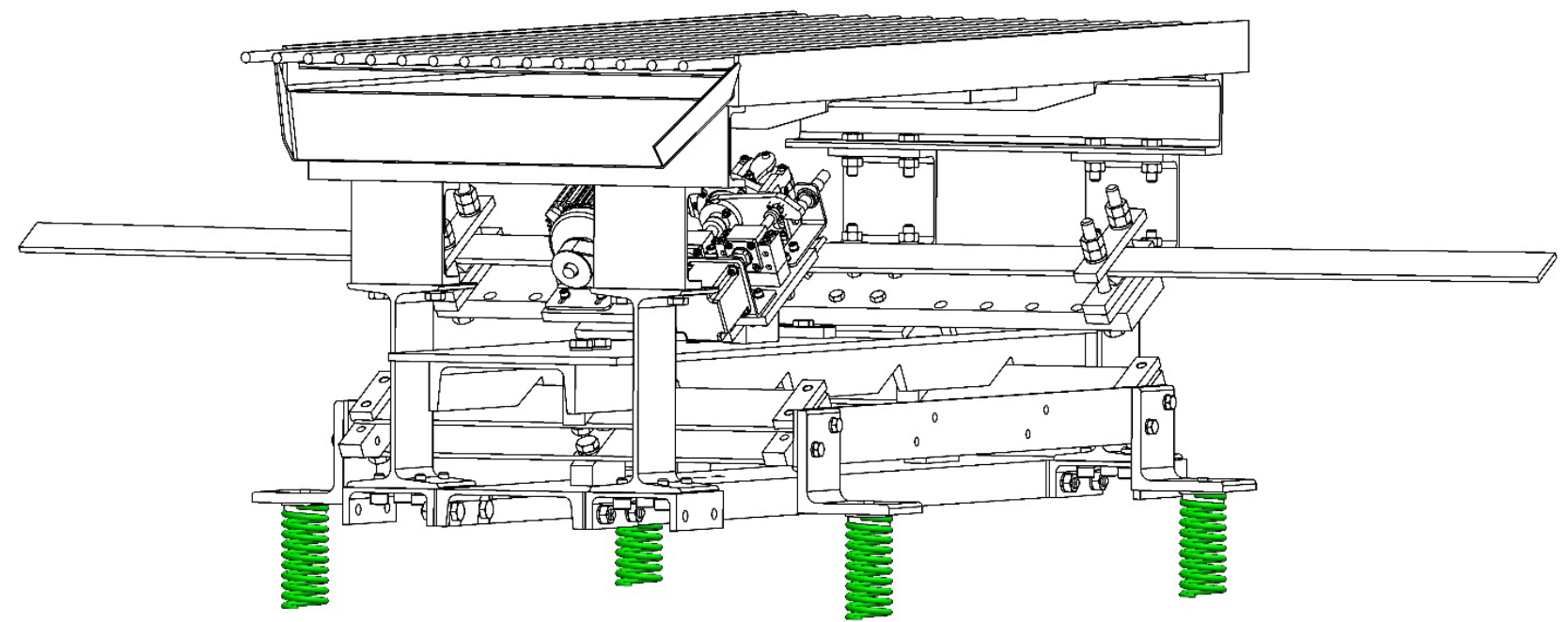

Fig. 2. General design of the vibratory conveyer-separator with the vibration isolation system presented in the form of four cylindrical coil springs

On the other hand, the stiffness (spring ratio) of the cylindrical coil spring can be determined as follows:

$$
c_{i z 1}=\frac{G \cdot d_{w}^{4}}{8 \cdot D_{m}^{3} \cdot i_{n}},
$$

where $G=8.4 \cdot 10^{10} \mathrm{~Pa}$ is the shear (rigidity) modulus of the steel $65 \Gamma ; d_{w}=6 \cdot 10^{-3} \mathrm{~m}$ is the diameter of the wire of the coli spring; $D_{m}=0.04 \mathrm{~m}$ is the central (pitch) diameter of the spring coil; $i_{n}$ is the number of coils (windings).

Based on Eq. (4), let us determine the number of the spring coils needed for ensuring the necessary stiffness of one vibration isolator:

$$
i_{n}=\frac{G \cdot d_{w}{ }^{4}}{8 \cdot D_{m}{ }^{3} \cdot c_{i z}}=\frac{8.4 \cdot 10^{10} \cdot 0.006^{4}}{8 \cdot 0.04^{3} \cdot 21933.2}=9.7 .
$$

Let us adopt 10 coils $\left(i_{n}=10\right.$, see Fig. 3$)$.

At first, let us consider the case of loading the coil spring by the following static (gravity) force:

$$
Q_{i z 1}=\left(\frac{m}{n}\right) g=\left(\frac{162.33}{4}\right) \cdot 9.807=397.978 \mathrm{~N} \text {. }
$$




\section{Oleksii Lanets, Oleksandr Kachur, Vitaliy Korendiy}

Applying the determined force to axially compress the cylindrical coil spring designed in SolidWorks software, and using the integrated finite-element method of simulation of the spring's stressstrain state, let us define the static deflection of the spring's free (loaded) end: $\delta_{i z}=1.829 \cdot 10^{-2} \mathrm{~m}$ (see Fig. 4). Then, let us calculate the spring ratio (stiffness) of the vibration isolator:

$$
c_{i z 1}=\frac{Q_{i z 1}}{\delta_{i z}}=\frac{351.495}{1.829 \cdot 10^{-2}}=21759.342 \mathrm{~N} / \mathrm{m} .
$$

Therefore, the natural frequency of free oscillations of the machine's single-mass system supported by four vibration isolators is following:

$$
v_{i z}=\frac{1}{2 \pi} \sqrt{\frac{c_{i z 1} \cdot n}{m}}=\frac{1}{2 \pi} \sqrt{\frac{21759.342 \cdot 4}{162.33}}=3.68 \mathrm{~Hz} .
$$
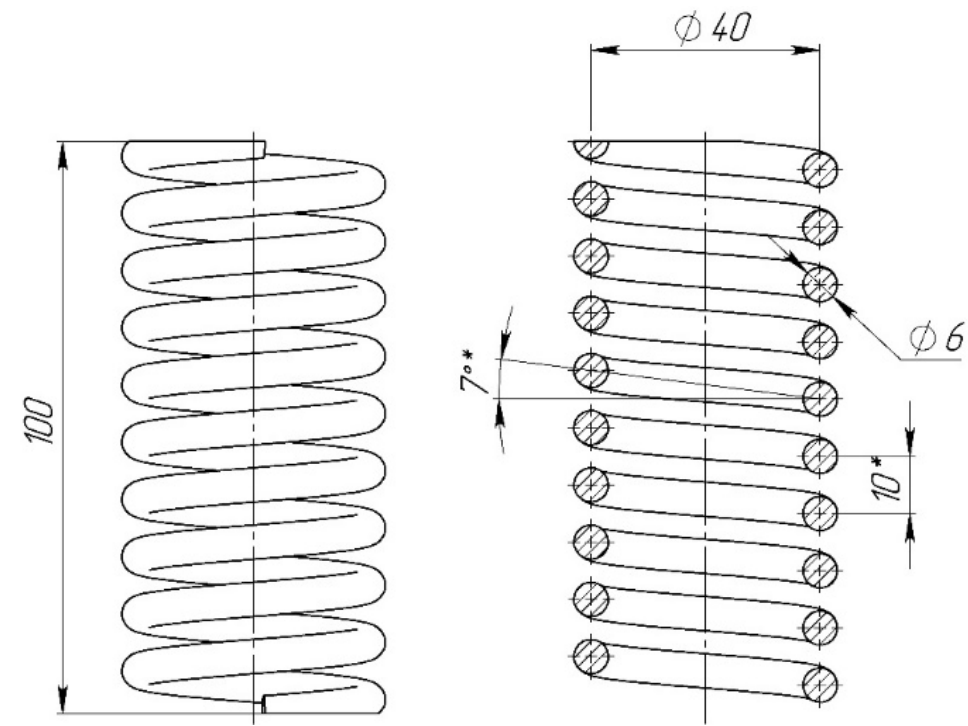

Fig. 3. Geometrical parameters of the cylindrical coil spring used as a vibration isolator

The loads exerted on the supports during the machine operation attended by its body vibrations suspended by the spring isolators are $z_{i z}^{2}$ times smaller than the loads which could be applied to the supports in the case when the resonance correction coefficient $z=1$ (with no vibration isolation). Therefore, in the presented calculations, there was used the value $z_{i z}=4.28$ causing significant reduction of the negative effect of the machine vibration on the foundation: the dynamic load exerted on the foundation is 18.3 times smaller than the one acting without any vibration isolation system. This fact allows us to conclude that the proposed springs provide the sufficient vibration isolation with no need of using the additional vibration-absorbing systems.

The stresses occurring in the coils of the spring (vibration isolator) are equal to [18]:

$$
\tau=\frac{8 \cdot Q_{i z 1} \cdot D_{m}}{\pi \cdot d_{w}{ }^{3}} \cdot k_{w}=\frac{8 \cdot 397.978 \cdot 0.04}{3.14 \cdot 0.006^{3}} \cdot 1.23=231 \mathrm{MPa},
$$

where $k_{w}$ is the coefficient of the coils curvature that can be determined as follows:

$$
k_{B}=\frac{4 \cdot\left(\frac{D_{m}}{d_{w}}\right)-1}{4 \cdot\left(\frac{D_{m}}{d_{w}}\right)-4}+\frac{0.65}{\left(\frac{D_{m}}{d_{w}}\right)}=\frac{4 \cdot\left(\frac{0.04}{0.006}\right)-1}{4 \cdot\left(\frac{0.04}{0.006}\right)-4}+\frac{0.65}{\left(\frac{0.04}{0.006}\right)}=1.23 .
$$

The calculated value of the stress in the spring coils is almost equal to the maximal one obtained by computer simulation in SolidWorks software. The difference between the theoretical and simulation results is smaller than $10 \%$. The obtained stress value is allowable for the springs made of the steel $65 \Gamma$. 


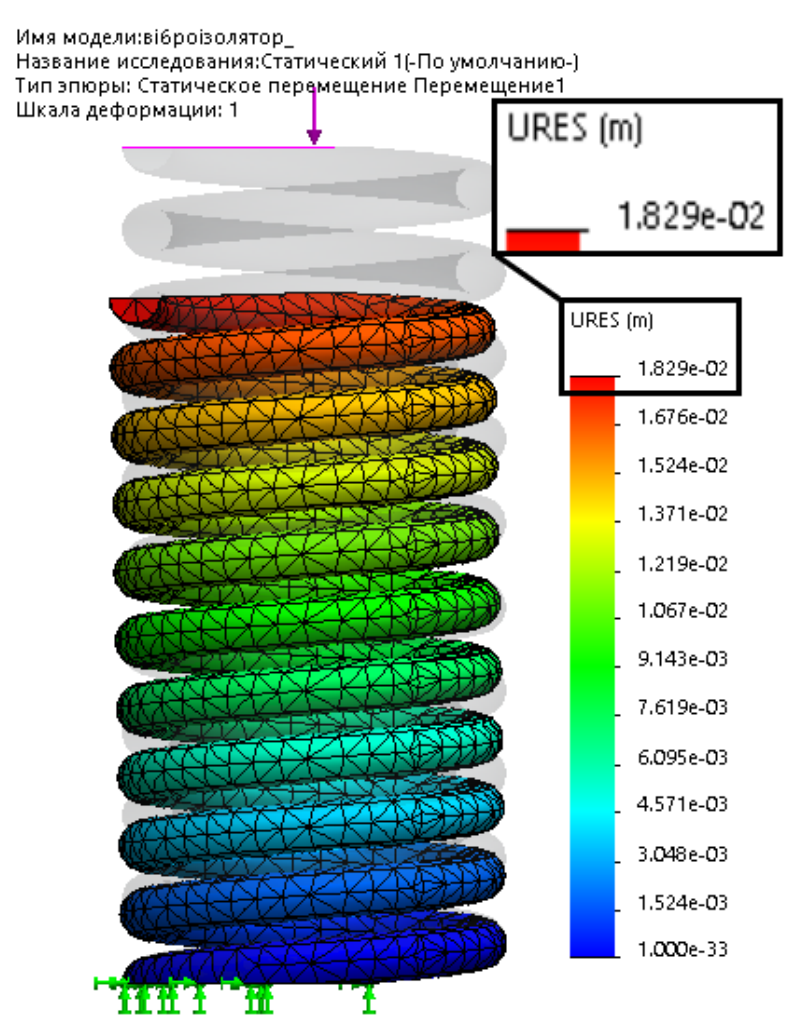

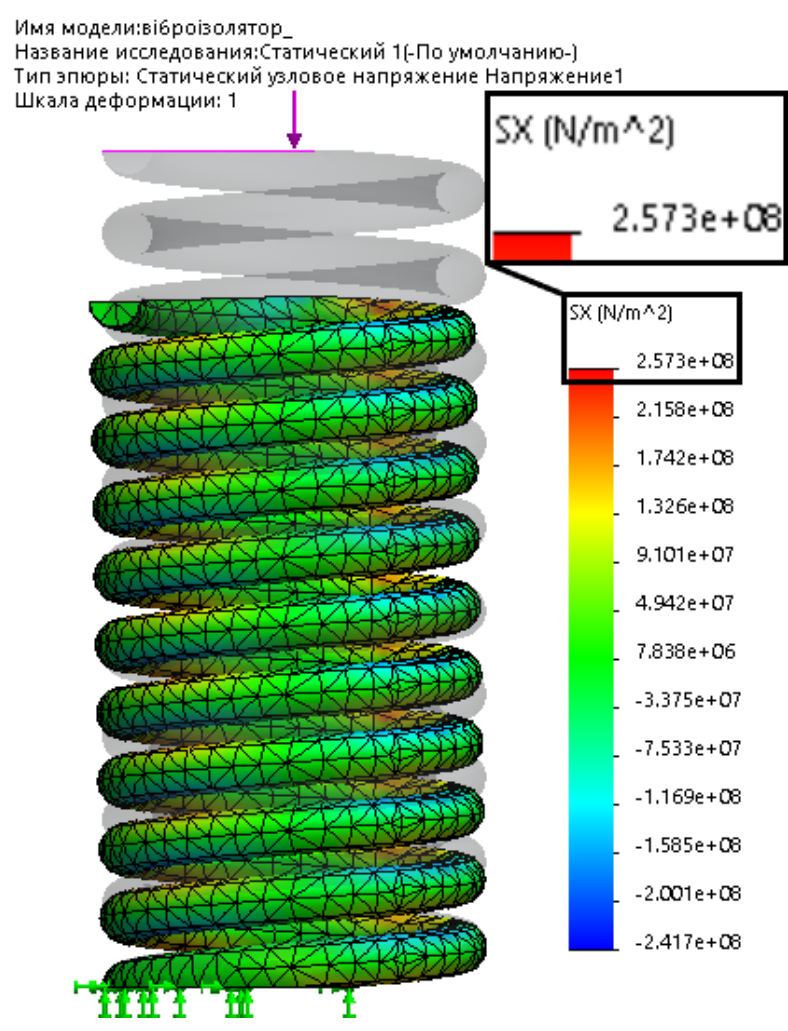

b

Fig. 4. The results of computer simulation of the spring stress-strain state under the action of the vertical axial load: $\mathrm{a}$ - the diagram of the spring deflection; $\mathrm{b}$ - the diagram of the stresses in coils

\section{Conclusions}

While designing vibration isolators, the essential attention should be paid to the safety factors such as the levels of vibration and noise, as well as to the material and the structure of isolators. In major vibratory technological equipment, there are used full-metal vibration isolators, which can be designed in the form of coil (cylindrical, conical, helico-spiral) or flat (leaf-type, disc-type) springs. The problems of stress-strain analysis of metal springs used for vibration isolation of various vibratory equipment are of urgent interest among the designers and researcher. The engineering techniques of step-by-step calculation of full-metal vibration isolators of different types of vibratory technological machines are not thoroughly presented in the modern information resources. The present paper is aimed at developing and implementing the detailed algorithm of determining the stiffness parameters of the metal coil springs used for vibration isolation of large-scale vibratory machines. The investigations are carried out using the basic laws and principles of solid mechanics and theory of vibrations. The calculations were conducted using MathCAD software; the computer simulation of the spring's stress-strain state was performed using SolidWorks software. The improved design of the vibratory conveyer-separator is considered. The engineering technique of calculating the passive vibration isolators of various vibratory equipment designed in the form of metal coil springs is developed. The proposed technique is implemented while designing the vibration isolation system of the vibratory conveyer-separator. The system's operational characteristics are determined, and the computer simulation of the springs stress-strain state is carried out. The proposed design of the vibratory conveyer-separator can be implemented in various industries (machine-building, chemical, pharmaceutical, food-processing, construction, mining, metallurgy, textile industries etc.) for conveying different loose, bulky and piecewise products, and separating them into fractions of different sizes. While carrying out further investigations, it is necessary to analyse the influence of the proposed design of vibratory conveyer-separator on the foundation during its operation, and to consider the necessary of applying the additional fixation systems. 


\section{Oleksii Lanets, Oleksandr Kachur, Vitaliy Korendiy}

\section{References}

[1] E. I. Rivin, "Vibration isolation of precision equipment", Precision Engineering, vol. 17, no. 1, pp. 41-56, 1995.

[2] A. Carrella, M. J. Brennan, T. P. Waters, "Static analysis of a passive vibration isolator with quasi-zerostiffness characteristic", Journal of Sound and Vibration, vol. 301, no. 3-5, pp. 678-689, 2007.

[3] I. Kovacic, M. J. Brennan, T. P. Waters, "A study of a nonlinear vibration isolator with a quasi-zero stiffness characteristic", Journal of Sound and Vibration, vol. 315, no. 3, pp. 700-711, 2008.

[4] N. Zhou, K. Liu, “A tunable high-static-low-dynamic stiffness vibration isolator”, Journal of Sound and Vibration, vol. 329, no. 9, pp. 1254-1273, 2010.

[5] G. N. Jazar, M. Mahinfalah, S. Deshpande, "Design of a piecewise linear vibration isolator for jump avoidance", Proceedings of the Institution of Mechanical Engineers, Part K: Journal of Multi-body Dynamics, vol. 221, no. 3, pp. 441-449, 2007.

[6] A. Narimani, M. E. Golnaraghi, G. N. Jazar, "Frequency Response of a Piecewise Linear Vibration Isolator", Journal of Vibration and Control, vol. 10, no. 12, pp. 1775-1794, 2004.

[7] Y. Q. Ni, J. M. Ko, C. W. Wong, S. Zhan, "Modelling and identification of a wire-cable vibration isolator via a cyclic loading test", Proceedings of the Institution of Mechanical Engineers, Part I: Journal of Systems and Control Engineering, vol. 213, no. 3, pp. 163-172, 1999.

[8] Y. Q. Ni, J. M. Ko, C. W. Wong, S. Zhan, "Modelling and identification of a wire-cable vibration isolator via a cyclic loading test Part 2: Identification and response prediction", Proceedings of the Institution of Mechanical Engineers, Part I: Journal of Systems and Control Engineering, vol. 213, no. 3, pp. 173-182, 1999.

[9] J. Winterflood, D. G. Blair, B. Slagmolen, "High performance vibration isolation using springs in Euler column buckling mode", Physics Letters A, vol. 300, no. 2-3, pp. 122-130, 2002.

[10] C.-M. Lee, V. N. Goverdovskiy, A. I. Temnikov, "Design of springs with "negative" stiffness to improve vehicle driver vibration isolation", Journal of Sound and Vibration, vol. 302, no. 4-5, pp. 865-874, 2007.

[11] J. Winterflood, T. Barber, D. G. Blair, "Using Euler buckling springs for vibration isolation", Classical and Quantum Gravity, vol. 19, no. 7, pp. 1-6, 2002.

[12] V. Dyrda, A. Kobets, I. Bulat, S. Slobodian, M. Lysytsia, S. Sokol, V. Lapin, H. Ahaltsov, "Present problems of vibration isolation in heavy mining machines at long-term cyclic loads", in Proc. $2^{\text {nd }}$ International Conference "Essays of Mining Science and Practice", vol. 168, Article Number 00042, 2020.

[13] V. Shekhovtsov, M. Lyashenko, P. Potapov, A. Diakov, K. Evseev, "Calculated and experimental tests of dynamic vibration isolators for use in the suspension system of the traction vehicle cabin", IOP Conference Series: Materials Science and Engineering, vol. 820, Article Number 012022, 2019.

[14] C. Yilmaz, N. Kikuchi, "Analysis and design of passive band-stop filter-type vibration isolators for lowfrequency applications”, Journal of Sound and Vibration, vol. 291, no. 3-5, pp. 1004-1028, 2006.

[15] D.-O. Lee, J.-H. Han, "A Comparison of Vibration Isolation Characteristics of Various Forms of Passive Vibration Isolator", Proceedings of the Korean Society for Noise and Vibration Engineering Conference, vol. 22, no. 9, pp. 817-834, 2012.

[16] A. Valeev, S. Kharisov, "Application of Vibration Isolators with a Low Stiffness for the Strongly Vibrating Equipment”, Procedia Engineering, vol. 150, pp. 641-646, 2016.

[17] W. Fiebig, J. Wróbel, "Two stage vibration isolation of vibratory shake-out conveyor", Archives of Civil and Mechanical Engineering, vol. 17, pp.199-204, 2017.

[18] O. Lanets, Osnovy rozrakhunku ta konstruyuvannya vibratsiynykh mashyn. Knyha 1. Teoriya ta praktyka stvorennya vibratsiynykh mashyn z harmoniynym rukhom robochoho orhana [Fundamentals of analysis and design of vibrating machines. Book 1. Theory and Practice of Development of Vibratory Machines with Harmonic Motion of the Working Element Body]. Lviv, Ukraine: Lviv Polytechnic Publishing House, 2018. [in Ukrainian]. 